\title{
Strategic Environmental Assessment and Sustainability in Europe - How Bright is the Future?
}

\section{Simon Marsden and Jan De Mulder}

\section{INTRODUCTION}

Strategic environmental assessment (SEA) is the evaluation of the impacts of policies, plans and programmes upon the environment. SEA is closely related to environmental impact assessment (EIA), which is the evaluation of the impacts of projects upon the environment. SEA should strengthen EIA (which is often applied late in the decision-making process), because it addresses impacts at higher or earlier levels of the process, and thereby aims to avoid them at the lower levels or at a later stage. It also specifically advocates integrating environmental factors into decision-making, in order to advance sustainability.

EIA and SEA were first required under the 1969 National Environmental Policy Act (NEPA) in the USA, ${ }^{1}$ and requirements for EIA are now common worldwide. Requirements for SEA have also been adopted by a number of countries, sometimes together with those for EIA, sometimes linked with those for EIA and sometimes separately. The purpose of this article is to look specifically at two of these requirements: Council Directive 2001/42/EC of 27 June 2001 on the Assessment of the Effects of Certain Plans and Programmes on the Environment (SEA Directive); ${ }^{2}$ and the Protocol on Strategic Environmental Assessment (SEA Protocol) ${ }^{3}$ to the United Nations Economic Commission for Europe's (UNECE) Espoo Convention on Environmental Impact Assessment in a Transboundary Context (Espoo Convention). ${ }^{4}$

Both of these legal instruments have been a long time coming. The SEA Directive has its origins in interest in

\footnotetext{
${ }^{1}$ National Environmental Policy Act (1969), 42 USC 4321-4347, found at <http://www.nrca.org/eias/index.htm>.

${ }^{2}$ Council Directive 2001/42/EC of 27 June 2001 on the Assessment of the Effects of Certain Plans and Programmes on the Environment, [2001] OJ L197 (SEA Directive), found at <http://europa.eu.int/comm/ environment/eia/sea-legalcontext.htm\#legal>

${ }^{3}$ Protocol on Strategic Environmental Assessment to the Convention on Environmental Impact Assessment in a Transboundary Context (Kiev, 23 May 2003).

${ }^{4}$ Convention on Environmental Impact Assessment in a Transboundary Context (Espoo Convention) (Espoo, 25 February 1991).
}

the European Commission going back over a decade; there has been a similar interest among parties to the UNECE (which includes the Member States of the European Community, as well as non-EC countries and a few others), with the publication of an influential SEA guide over one decade ago. ${ }^{5}$

Whilst the institutionalization of SEA in these legal instruments means a considerable step forwards to scrutinize governmental plans and programmes, administrations and 'experts' continue to struggle to develop appropriate methodological approaches to implement these instruments. It seems to be difficult for SEA practitioners to get out of the shadow of the classical EIA tradition. One of the reasons might be that the provisions of both legal SEA instruments reflect a great similarity with the stages of the EIA process: screening, scoping, drafting the report, reviewing the report and its use by the public during the inquiry about the permit application, and the final decision about the proposed activity, after which monitoring may follow. It should also be mentioned that the 5-year review of the EIA Directive by the European Commission ${ }^{6}$ has revealed that implementation remains problematic with respect to a number of issues, such as scoping, the study of alternatives and the quality of reports. So it is no surprise that the EIA Directive relates to the main areas of EC legislation in which complaints cases and the resultant infringements are found. As of May 2004, there were 225 open complaints cases, of which there were 68 infringements. This implementation deficit should not be neglected and may be considered as a warning signal regarding the legal future of SEA.

One should also not overlook the fact that in the USA, NEPA was not very successful, which may hold lessons

\footnotetext{
${ }^{5}$ United Nations Economic Commission for Europe, Application of Environmental Assessment Principles to Policies, Plans and Programmes (United Nations, 1992).

${ }^{6}$ Report from the Commission to the European Parliament and the Council on the Application and Effectiveness of the EIA Directive (Directive 85/337/EEC, as amended by Directive 97/11/EC): How Successful are the Member States in Implementing the EIA Directive? (European Commission, undated), found at <http://europa.eu.int/ comm/environment/eia/report_en.pdf>.
} 
for the success of SEA in Europe. Underwood and Alton state:

... Like the SEA-Directive, NEPA created a broadly scoped and dynamic environmental accounting tool within the US. However, the US governmental agencies have struggled with the application of NEPA. There has been an extreme reluctance to utilize NEPA's full capacity for over three decades ... ${ }^{7}$

\section{SEA, ENVIRONMENTAL POLICY INTEGRATION AND SUSTAINABLE DEVELOPMENT}

Noble has rightly identified the key component of SEA as strategy, which he defines as 'the art of the general; the prelude to the beginning; the determination of objectives and means, and the adoption of courses of action to achieve specific ends'. ${ }^{8}$ Based upon an application of strategic characteristics to specific SEAs, Noble defines SEA as follows, emphasizing the importance of alternatives and outcomes:

SEA is the proactive assessment of alternatives to proposed or existing policies, plans and programs, in the context of a broader vision, set of goals, or objectives to assess the likely outcomes of various means to select the best alternatives(s) to reach desired ends. ${ }^{9}$

SEA can play a significant role in enhancing the integration of environmental considerations in policy and planning processes because it is directed at strategic decision making. The general benefits of SEA are that it can help decision makers by first of all achieving environmentally sound and sustainable development, and furthermore by:

- strengthening policy, plan and programme-making processes;

- saving time and money by avoiding costly mistakes; and

- improving good governance and building public trust and confidence in decision making. ${ }^{10}$

The European Commission, in the lead up to the SEA Directive coming into force, took a keen interest in 'these advantages', commissioning a three-volume report into 'the way in which environmental considerations

\footnotetext{
${ }^{7}$ P.B. Underwood and C.A. Alton, 'Could the SEA Directive Succeed Within the United States?', 23:3 Environmental Impact Assessment Review (2003), 260.

${ }^{8}$ B.F. Noble, 'Strategic Environmental Assessment: What is it? And What Makes it Strategic?', 2:2 Journal of Environmental Assessment Policy and Management (2000), 206.

${ }^{9}$ lbid., at 215.

${ }^{10} \mathrm{~J}$. Dusik, T. Fischer, and B. Sadler, Benefits of a Strategic Environmental Assessment (UNDP-REC, 2003), at 5.
}

are included in policy, plan and programme decisionmaking in all sectors ... rather than simply raising the profile of environmental policies within government and institutional agendas'. ${ }^{11}$ The report is concerned with a wide range of matters, including existing experience with SEA worldwide, but the main objective of the report is arguably to inform implementation strategies for the Directive.

Among many others, Dalal-Clayton and Sadler have argued that SEA is needed to advance the sustainability agenda. ${ }^{12}$ Quite what this means is open to debate. Dovers has argued that what is required is for SEA 'to play a significant part in the policy and institutional challenge of sustainability', ${ }^{13}$ what he calls 'deep SEA'. Deep SEA can be contrasted with 'shallow SEA' in that the latter is concerned with scoping environmental impacts of classes of developments or regional resource and environmental management issues, often from the private sector. It does this by simply applying EIA to plans and programmes, rather than being concerned to challenge the process itself, particularly to address the policy process and the institutional restraints to which it is subject. Dovers distinguishes between firstorder (direct) and second-order (indirect) impacts: an example of first order impacts is biodiversity loss; an example of second-order impacts is land clearance. There is little point in preventing biodiversity loss if land is still being cleared; without a habitat many species will simply end up in zoos or on isolated reserves, if not extinct. Deep SEA addresses the latter as well as the former:

As well as dealing with second-order impacts, a key characteristic of deep SEA is that the main focus is on government policies and actions, not on development proposals from the private sector. This is because ... public policy, institutions and law are enormously influential in shaping society and hence are crucial targets for assessment ... it is doubly important to establish as a target for SEA, because broad government policy directions are more likely to escape proper assessment by government than any private sector proposals. ${ }^{14}$

${ }^{11}$ ICON, SEA and Integration of the Environment into Strategic Decision-Making (Imperial College Consultants Ltd, 2001), Vol. 1, at i. ${ }^{12}$ B. Dalal-Clayton and B. Sadler, 'Strategic Environmental Assessment: A Rapidly Evolving Approach', working paper (International Institute for Environment and Development, undated). B. Dalal-Clayton and B. Sadler are currently working on an overview of SEA, with a special focus on developing countries and countries in transition, and its potential role as a key tool for strategies for sustainable development and poverty reduction. See B. Dalal-Clayton and B. Sadler, 'The Status and Potential of Strategic Environmental Assessment (SEA)' (draft of 17 September 2003), found at <http:// www.iied.org/spa/sea.html>.

${ }^{13}$ S. Dovers, 'Too Deep a SEA: Strategic Environmental Assessment in the Era of Sustainability', in S. Marsden and S. Dovers, Strategic Environmental Assessment in Australasia (The Federation Press, 2002), at 43.

${ }^{14}$ Ibid., at 26. 
TABLE A CONDITIONS NEEDED FOR SEA TO PROMOTE SUSTAINABILITY (PARTIDARIO AND CLARK $)^{16}$

- A policy framework is in place, establishing the articulation across sectoral policies and institutional contexts.

- Credible and feasible alternatives [are considered] that allow evaluation of a decision based on comparable rather than absolute values.

- [There is] recognition that uncertainty characterizes any policy and planning decision.

- Simple though pragmatic indicators [are used] that can assist monitoring of the decisions to determine actual effects.

- Good communications mechanisms [exist] to ensure that all partners in the SEA process are adequately involved and their perspectives contemplated.

While the SEA Directive and Protocol are primarily concerned with direct effects from government plans and programmes (the Protocol also can focus on policies and legislation), indirect effects must also to be addressed; illustrating elements of both shallow and deep SEA. ${ }^{15}$ In this context, Partidario and Clark suggest that SEA can play a role towards sustainability if a number of conditions (outlined in Table A) are met.

A national sustainable development strategy is commonly used to set the policy framework and to ensure that environmental protection requirements are integrated into policies, plans and programmes for specific sectors. Sustainable development indicators are sometimes used to monitor the effects of decisions upon the environment. Although a lot of work has already been done on indicators,${ }^{17}$ their further development is essential to assess and report on progress in achieving environmental goals. In relation to specific environmental issues and/or media, indicators are required that focus on the state of the environment, driving forces and pressures. Assessing progress in relation to environmental integration across economic sectors requires the development of tailored sets of indicators (such as along the lines of Transport and Environment Reporting Mechanism (TERM) in the EU). ${ }^{18}$ Similar work is being undertaken by the

\footnotetext{
15 'Effects' under both the SEA Directive (Annex I) and Protocol (Annex IV) include 'secondary, cumulative, synergistic, short-, medium- and long-term, permanent and temporary, positive and negative effects'. ${ }^{16}$ M.R. Partidario, and R. Clark, 'Introduction', in M.R. Partidario and R. Clark (eds), Perspectives on Strategic Environmental Assessment (CRC-Lewis, 2000), at 5.

${ }_{17}$ See, for instance, the UN-CSD Theme Indicator Framework, found on the CSD website at <http://www.un.org/esa/sustdev/ natlinfo/indicators/isdms2001/table_4.htm>.

${ }^{18}$ European Environment Agency, Towards a Transport and Environment Mechanism for the EU - Part 2: Some Preliminary Indicator Sheets (EEA, 1999), found at <http://reports.eea.eu.int/TEC18-2/en>.

European Environment Agency in relation to other sectors such as agriculture, tourism and energy. ${ }^{19}$

Both these and other conditions will be considered below in relation to the SEA Directive and SEA Protocol. A recent publication from the Organization for Economic Cooperation and Development (OECD) on the results of sustainable development has clearly indicated that EIA is playing and SEA is expected to play a role in such a policy:

\begin{abstract}
All OECD countries have procedures for environmental impact assessments of large projects, usually combining scientific evaluation and extensive public consultation, before a final decision can be made. While countries are increasingly using strategic environmental assessment, much remains to be done to ensure that sectoral policies (such as agricultural and energy policies) take into account their environmental consequences. ${ }^{20}$
\end{abstract}

\section{SEA DIRECTIVE}

The SEA Directive contains 20 recitals, 15 articles and two annexes. It is binding upon the 25 Member States of the European Community. For the purposes of this article, the important provisions are Recitals 1 and 2 (which provide the context of sustainability), and Article 1, which set out the objectives.

Recital 1 of the Directive refers to Article 174 of the Treaty on European Union, ${ }^{21}$ which provides that Community policy on the environment is to contribute to the preservation, protection and improvement of the quality of the environment, the protection of human health and the prudent and rational utilization of natural resources and that it is based on the precautionary principle. Recital 1 also refers to Article 6 of the Treaty, which provides that environmental protection requirements are to be integrated into the definition of Community policies and activities, with a view to promoting sustainable development. Recital 1 therefore provides the policy framework for SEA to play a role towards sustainability. In basing itself firmly on the precautionary principle, the Community policy on the environment also recognizes that uncertainty characterizes any policy and planning decision.

Recital 2 of the Directive refers to the Fifth Environment Action Programme (EAP): Towards Sustainability $-a$ European Community Programme of Policy and Action

\footnotetext{
${ }^{19}$ European Environment Agency, Indicators (EEA, undated), found at <http://themes.eea.eu.int/indicators/>.

${ }^{20}$ Organization for Economic Cooperation and Development, Implementing Sustainable Development: Key Results 2001-2004 (OECD, May 2004), at 10, found at <http://www.oecd.org/dataoecd/ 25/35/31683750.pdf>

${ }^{21}$ Treaty on European Union (Maastricht, 7 February 1992), [2002] OJ C325.
} 
in Relation to the Environment and Sustainable Development ${ }^{22}$ as supplemented by the Council decision on its review, which affirmed the importance of SEA. ${ }^{23}$ Also, the Sixth EAP pays attention to SEA (and EIA), ${ }^{24}$ requiring the full and effective use and implementation of EIA and SEA as one of the further efforts for the integration of environmental protection requirements into the preparation, definition and implementation of Community policies and activities (Article 3, paragraph 3).

Article 1 of the SEA Directive, in setting out objectives, recognizes the importance of the sustainable development context provided by Articles 174 and 6 of the Treaty, as cited in the recitals. Article 1 states:

The objective of this Directive is to provide for a high level of protection of the environment and to contribute to the integration of environmental considerations into the preparation and adoption of plans and programmes with a view to promoting sustainable development, by ensuring that, in accordance with this Directive, an environmental assessment is carried out of certain plans and programmes which are likely to have significant effects on the environment.

Annex I(e) of the Directive states that the environmental report that is required under Article 5 must outline 'the environmental protection objectives established at international, Community or Member State level, which are relevant to the plan or programme and the way those objectives and any environmental considerations have been taken into account during its preparation'. This is significant because it highlights that Community environmental policy cannot be viewed in a vacuum; rather it is subject to international law and policy, where relevant. This is seen also in Recitals 3 and 7 of the Directive, which recognize the role of SEA in international law. ${ }^{25}$ Recital 3 refers to the Convention on Biological Diversity (CBD) ${ }^{26}$ which requires parties to integrate as far as possible and appropriate the conservation and sustainable use of biological diversity into relevant sectoral and cross-sectoral plans and programmes. Recital 7 refers to the Espoo Convention (discussed briefly below).

\footnotetext{
${ }^{22}$ Commission Communication of 27 March 1992, Towards Sustainability: A European Community Programme of Policy and Action in relation to the Environment and Sustainable Development, COM (92) 23 final.

${ }^{23}$ Decision No 2179/98/EC of the European Parliament and of the Council of 24 September 1998 on the Review of the European Community Programme of Policy and Action in relation to the Environment and Sustainable Development, Towards Sustainability, [1998] OJ L275.

${ }^{24}$ Commission Communication of 24 January 2001 on the Sixth Environment Action Programme of the EC, COM (2001) 31 final.

${ }^{25} \mathrm{~S}$. Marsden, 'SEA and International Law: An Analysis of the Effectiveness of the SEA Protocol to the Espoo Convention, and of the Influence of the SEA Directive and Aarhus Convention on its Development', 1 Environmental Law Network International Review (2002), at 1.

${ }^{26}$ Convention on Biological Diversity (Rio de Janeiro, 5 June 1992).

Annex II of the Directive outlines criteria for determining significant effects, where SEA under the Directive is not mandatory (under Article 3(2)), but discretionary (under Article 3(3)-(4)). These criteria include 'the relevance of the plan or programme for the integration of environmental considerations in particular with a view to promoting sustainable development' and 'the relevance of the plan or programme for the implementation of Community legislation on the environment' (e.g. plans and programmes linked to waste management or water protection).

The application of the Directive is limited in scope, but is closely related to Directive 85/337/EEC (as amended) on the Assessment of the Effects of Certain Public and Private Projects on the Environment (the EIA Directive). ${ }^{27}$ This is explained in the SEA Directive Guidance. ${ }^{28}$ Not only are policies excluded, but there are strict criteria established in Articles 2 and 3 which emphasize that plans and programmes must be formally required and be prepared for listed sectors (which must, in turn, set the framework for future development consent of projects under the EIA Directive), or must be plans which must be assessed under Directive 92/43/EEC on the Conservation of Natural Habitats and of Wild Flora and Fauna (the Habitats Directive). The sectors listed in SEA Directive Article 3 usually requiring assessment are: agriculture, forestry, fisheries, energy, industry, transport, waste management, water management, telecommunications, tourism, town and country planning or land use. These are subject to review, together with the types of plans and programmes, as Article 12(3) of the Directive contains a provision that is designed to further improve integration. This states:

With a view further to integrating environmental protection requirements, in accordance with Article 6 of the Treaty, and taking into account the experience acquired in the application of this Directive in the Member States ... a report [on the application and effectiveness of this Directive will be provided before 21 July 2006, and] will be accompanied by proposals for amendment of this Directive, if appropriate. In particular, the Commission will consider the possibility of extending the scope of this Directive to other areas/sectors and other types of plans and programmes.

De Mulder states that the SEA Directive is 'an important step towards the realization of a concrete integration

\footnotetext{
${ }^{27}$ See the European Commission, Environmental Impact Assessment (European Commission, undated), found at <http://europa.eu.int/comm/ environment/eia/eia-legalcontext.htm\#legalcontext>. See also generally, L. Feldmann, M. Vanderhaegen, and C. Pirotte, 'The EU's SEA Directive: Status and Links to Integration and Sustainable Development', 21:3 Environmental Impact Assessment Review (2001), 203.

${ }^{28}$ Representatives of Member States and the Environment DirectorateGeneral of the European Commission, Implementation of Directive 2001/ 42 on the Assessment of the Effects of Certain Plans and Programmes on the Environment (23 September 2003), found at <http://europa.eu.int/ comm/environment/eia/030923_sea_guidance.pdf>.
} 
approach'. ${ }^{29} \mathrm{He}$ draws attention to the integration of environmental concerns in planning processes that the SEA Directive will contribute towards and states that 'a more integrated system of planning means that environmental criteria are incorporated throughout the planning process, which could help to implement the concept of sustainable development'. ${ }^{30}$

The question remains, of course, whether this opportunity will be used by the Member States when transposing and applying the SEA Directive. Article 4(2) of the SEA Directive stipulates that:

The requirements of this Directive shall either be integrated into existing procedures in Member States for the adoption of plans and programmes or incorporated in procedures established to comply with this Directive.

From a formal perspective and based on efficiency considerations, it is obvious that the 'integration track' in Article 4(2) offers advantages, but this approach does not guarantee an effective outcome with respect to the integration of environmental considerations. Communications between experts at EU-level meetings indicate that the ongoing discussions on preparing draft SEA legislation in the different Member States are very much about the tension between the environment administration and the other policy fields regarding the assurance of an effective SEA process within the existing planning procedures.

The Commission's SEA Directive Guidance remains extremely formal when elaborating the meaning of Article 4(2) and refers only to 'planning procedures' and the opportunity to avoid overlap. ${ }^{31}$ Also, the fact that the SEA Directive Guidance describes 'the environmental report' as required by Article 5 of the SEA Directive as the central part of the environmental assessment has to be considered as a legacy of the EIA approach. ${ }^{32}$ The Guidance continues as follows:

... The environmental report is an important tool for integrating environmental considerations into the preparation and adoption of plans and programmes since it ensures that their likely significant effects on the environment are identified, described and assessed and taken into account in that process. ${ }^{33}$

However, as the EIA practice of the past decades offers numerous examples of the fact that even a good report or environmental impact statement does not ensure that environmental concerns are taken into account in the final decision, so there is no reason to

\footnotetext{
${ }^{29} \mathrm{~J}$. De Mulder, 'The New Directive on Strategic Environmental Assessment', 1 Environmental Law Network International Review (2001), at 19.

${ }^{30} \mathrm{Ibid}$., at $14-15$.

${ }^{31}$ See Representatives of Member States, n. 28 above, at 21-22.

32 lbid., at 23.

${ }^{33}$ Ibid., at 23

(c) Blackwell Publishing Ltd. 2005.
}

believe that the SEA process would be more successful. On the contrary, SEA experts keep on repeating that an effective SEA requires approaches that are different. Partidario favours a so-called top-down approach. ${ }^{34}$ This means that the scope of a SEA is designed or developed around national strategies or environmental and sustainability objectives. In the next stage, the particular objectives, options and alternatives are the subject of an assessment. The assessment has to result in the formulation of a context for the development of solutions in order to address the initial policy problems. This approach differs from a SEA (bottom-up) approach (similar to the EIA approach) that is done after the policy proposals - including alternatives - have been formulated. Such an approach leads primarily to mitigation of the effects of proposed measures.

The top-down approach also requires other skills and methods of work and focuses the assessment work differently. Nitz and Brown have described this as follows:

EA practitioners need to become familiar with the policy process, and there is a body of literature and practice within the policy sciences to assist with this. Environmental assessment practitioners must:

- understand the stages of policy making and identify the activities and issues that will be addressed within each stage;

- identify when and by which actors, decisions are made within different stages of the policy-making process (decision scoping), and the appropriate form and content of environmental information that should be available at these decision points; and

- mould the content and form of SEA to contribute to these decisions. This moulding will have to be specific to each particular policy making context. ${ }^{35}$

Returning to Partidario and Clark's conditions, which must be met if SEA is to play a role towards sustainability, aside from the sustainable development framework and the recognition of uncertainty (discussed above), each of these conditions is provided for by the Directive itself. Alternatives must be analysed in accordance with Article 5, which concerns the environmental report. 'Reasonable alternatives' to the likely significant effects on the environment of implementing the plan or programme must be considered, 'taking into account the objectives and the geographical scope of the plan or programme'. Annex I of the Directive provides more detail on what the environmental report must contain. Annex I(h) includes a requirement to provide

\footnotetext{
${ }^{34}$ M. Partidario, 'SEA Methodological approaches', BEACON Workshop, Brussels, (24 June 2004).

${ }^{35}$ T. Nitz and A.L. Brown, 'SEA must learn how policy making works', 3:3 Environmental Assessment Policy and Management (2001), 340. See also L. Brown and T. Nitz, 'Applying SEA to policy making: The policy cycle model and the Queensland Policy Handbook' in S. Marsden and S. Dovers, n. 13 above, at 84-98.
} 
an 'outline of the reasons for selecting the alternatives dealt with, and a description of how the assessment was undertaken including any difficulties (such as technical deficiencies or lack of know-how) encountered in compiling the required information'.

Article 6 of the Directive is concerned with consultation, which is the last of Partidario and Clark's conditions. Article 6 implements the UNECE Aarhus Convention on Access to Information, Public Participation in Decision-Making and Access to Justice in Environmental Matters, which has been a significant influence upon the SEA Directive. ${ }^{36}$ The Directive requires that authorities designated by Member States on the basis of their specific environmental responsibilities, must be consulted in determining whether certain plans or programmes are to be assessed in determining the scope and level of information to be contained within the environmental report, and on the draft plan or programme and environmental report. The public must also be consulted on the draft plan or programme and environmental report if the public is 'affected by, or having an interest in, the decision-making. ${ }^{37}$ With regard to the public participation requirements of the SEA Directive, there has been criticism for a failure to comply with Article 7 of the Aarhus Convention. ${ }^{38}$

Finally, in relation to Partidario and Clark's conditions set out in Table A, Article 10 of the Directive provides for significant environmental effects of the implementation of plans or programmes to be monitored, in order that unforeseen adverse effects can be identified at an early time, and in order to carry out remedial action where needed. Annex I(i) requires that monitoring measures must be described as part of the environmental report, and Annex I(g) requires the report to outline the measures envisaged to prevent, reduce and as fully as possible offset any significant adverse effects .... With regard to the use of indicators to monitor effects, these can be based on the criteria that the Directive sets out to determine the likely significance of effects. The criteria are set out in Annex II, and are of two types: characteristics of the

\footnotetext{
${ }^{36}$ See J. De Mulder, n. 29 above, at 17-18. See the Convention on Access to Information, Public Participation in Decision-Making and Access to Justice in Environmental Matters (Aarhus, 25 June 1998). ${ }^{37}$ See SEA Directive, n. 2 above, Article 6.1 and 6.4.

${ }^{38}$ See A. Mathiesen, 'Public Participation in Decision Making and Access to Justice in EC Environmental Law: The Case of Certain Plans and Programmes', 12:2 European Environmental Law Review (2003), 46. Under Article 7 of the Aarhus Convention, each party must introduce appropriate practical and/or other provisions for the public to participate during the preparation of plans and programmes relating to the environment, within a transparent and fair framework, having provided the necessary information to the public. The relevant public authority must designate the public, taking into account the objectives of the Convention, before it is able to participate. To the extent appropriate, each party must also endeavour to provide opportunities for public participation in the preparation of policies relating to the environment.
}

plans and programmes, and characteristics of the effects and the area likely to be affected.

With regard to the decision-making process itself, Articles 8 and 9 are of relevance. Article 8 provides that the environmental report, opinions expressed on it and results of any transboundary consultations must be taken into account during the preparation of the plan or programme. Article 9 requires that Member States must inform the designated authorities and public of the plan or programme subsequently adopted, including information on how environmental considerations have been integrated into the plan or programme, and how the environmental report, opinions and consultations have been taken into account. Information must also be disclosed on the reasons for choosing the plan or programme adopted, and of the monitoring measures decided upon. These are significant provisions as they are directed to transparent and accountable decision-making.

The first review by the European Commission of the SEA Directive is scheduled for 2006. The question remains whether there will by then be sufficient practical experience with the application of the requirements. As N. Risse et al. observed: 'the general requirements prescribed by the Directive are not restrictive and leave ample room for creativity, flexibility and adaptability to suit each Member State's context'. ${ }^{39}$

At the same time, the Commission has initiated a study on the relationship between the EIA and SEA Directives and, when complete, an experts' working group will recommend possible amendments to the EIA Directive. This could be a first move towards integrating the two directives. As Sheate has suggested: ‘.. This coincidence of the review processes provides an early opportunity to consider the consolidation of both directives as a coherent whole'. ${ }^{40}$

An additional consideration regarding the possible merging of the directives is the way the Commission deals with these instruments. This can be illustrated by the approach of DG Transport and Energy and in particular the new TEN-T Guidelines adopted by the European Parliament and the Council on 21 April $2004 .{ }^{41}$ According to Article 8.2 of the Guidelines, the Commission shall:

\footnotetext{
${ }^{39} \mathrm{~N}$. Risse et al., 'Implementing the European SEA Directive: The Member States' margin of discretion', 23:4 Environmental Impact Assessment Review (2003), 467.

${ }^{40}$ W. Sheate, 'The EC Directive on Strategic Environmental Assessment: A much-needed boost for environmental integration', 12:12 European Environmental Law Review (December 2003), at 347.

${ }^{41}$ Regulation No 807/2004 of the European Parliament and of the Council of 21 April 2004 amending Council Regulation (EC) No 2236/ 95 laying down general rules for the granting of Community financial aid in the field of trans-European networks, [2004] OJ L143.
} 
.. By 21 July 2004 .. in agreement with Member States, develop suitable methods for implementing the strategic environmental assessment with the objective of ensuring, inter alia, appropriate coordination, avoiding duplication of effort, and achieving simplification and acceleration of planning processes for cross-border projects and corridors. ${ }^{42}$

\section{SEA PROTOCOL}

The SEA Protocol is binding upon the parties to the Espoo Convention that have signed it. These include 37 States and the European Community. In common with the link between the SEA and EIA Directives, the SEA Protocol is linked with another international instrument, the Espoo Convention, which shares the same Secretariat, and the Aarhus Convention, the requirements of which are largely incorporated into the SEA Protocol. While Espoo is concerned specifically with transboundary impacts from projects, the SEA Protocol is not, as some may suspect, limited to transboundary impacts from plans and programmes. Rather, it operates as a stand-alone instrument, and is concerned with impacts from plans and programmes within a State, with consideration of transboundary effects being a secondary concern.

The Protocol contains eight recitals, 26 articles and five annexes. The first recital recognizes the importance of integrating environmental, including health, considerations into the preparation and adoption of plans and programmes and, to the extent appropriate, policies and legislation. The second recital commits the parties to promoting sustainable development, based in particular upon the conclusions of the United Nations Conference on Environment and Development (UNCED), especially Principles 4 and 10 of the Rio Declaration on Environment and Development, ${ }^{43}$ together with the outcome of the third Ministerial Conference on Environment and Health ${ }^{44}$ and the World Summit on Sustainable Development. ${ }^{45}$ These developments arguably provide the policy framework needed because they place the objective of the Protocol (described below) within a sustainable development context agreed by the international community,

\footnotetext{
${ }^{42}$ When completed, the Guidelines will be available at <http:/l www.europa.eu.int/comm/environment/eia/sea-support.htm>.

${ }^{43}$ See the Rio Declaration on Environment and Development, UN Doc. A/CONF.151/26/Rev. 1 (Vol I) (Rio de Janeiro, 1992).

${ }^{44}$ European Commission and World Health Organization Regional Office for Europe, Declaration of Third Ministerial Conference on Environment and Health (London, 16-18 June 1999).

${ }^{45}$ See Johannesburg Declaration, Report of the World Summit on Sustainable Development (Johannesburg, South Africa, 26 August4 September 2002), UN Doc. A/CONF.199/20, Resolution 1, Annex; and Johannesburg Plan of Implementation, Report of the World Summit on Sustainable Development (Johannesburg, South Africa, 26 August-4 September 2002), UN Doc. A/CONF.199/20, Resolution 2, Annex.
}

including the emphasis placed by the Protocol upon environmental health. However, as seen below, the framework is significantly weaker than that provided for the SEA Directive.

The third and fifth recitals recognize the importance of the Espoo and Aarhus Conventions respectively, with the sixth emphasizing the importance of public participation, which is the final criterion in Partidario and Clark's criteria in Table A. The fourth recital stresses the role of SEA:

Recognizing that strategic environmental assessment should have an important role in the preparation and adoption of plans, programmes, and, to the extent appropriate, policies and legislation, and that the wider application of the principles of environmental impact assessment to plans, programmes, policies and legislation will further strengthen the systematic analysis of their significant environmental effects ...

The objectives of the SEA Protocol are found in Article 1, which states:

The objective of this Protocol is to provide for a high level of protection of the environment, including health, by:

(a) ensuring that environmental, including health, considerations are thoroughly taken into account in the development of plans and programmes;

(b) contributing to the consideration of environmental, including health, concerns in the preparation of policies and legislation;

(c) establishing clear, transparent and effective procedures for strategic environmental assessment;

(d) providing for public participation in strategic environmental assessment;

(e) integrating by these means environmental, including health, concerns into measures and instruments designed to further sustainable development.

With regard to the role of the SEA Protocol in 'further[ing] sustainable development', outlined in Article 1(e), De Mulder is highly critical. He states that:

Although the considerations in the preamble refer to the WSSD outcome (Johannesburg, 2002), the objectives of the SEA Protocol are not clearly situated within a policy framework aimed at sustainable development. Given the absence of SEA in the meagre WSSD Plan of Implementation, perhaps one should not be surprised. ${ }^{46}$

This is significant because while some international instruments recognize the importance of SEA (such as the CBD), and while the SEA Directive is clearly situated in a sustainability framework of the Treaty and Action Programmes of the European Union, which recognizes

\footnotetext{
${ }^{46} \mathrm{~J}$. De Mulder, 'The New UNECE Protocol on Strategic Environmental Assessment', 2 Environmental Law Network International Review (2003), 13.
} 
the role of SEA in taking the agenda forward, ${ }^{47}$ this may not the case with the SEA Protocol, especially given the much-criticized WSSD outcomes. ${ }^{48}$

Of other provisions, and as also seen in the recitals, of immediate note is that while the Protocol is directed at plans and programmes (see Article 4), Article 13(1) provides that:

Each Party shall endeavour to ensure that environmental, including health, concerns are considered and integrated to the extent appropriate in the preparation of its proposals for policies and legislation that are likely to have significant effects on the environment, including health.

While this is a discretionary provision, it is given weight because Article 13(4) requires that:

Each Party shall report to the Meeting of the Parties to this Convention serving the Meeting of the Parties to this Protocol on its application of this article.

De Mulder comments on Article 13(4) that it 'is intended to push parties towards the implementation of this article'. ${ }^{49}$

The title of the Protocol gives additional substance to this conclusion. The 'SEA Directive' is so-called by those seeking to shorten the title and with a view to emphasize the original broad aspirations of its early drafters. While plans and programmes are strategic decisions, they are not as strategic as policies and legislation, as they are not the highest levels of decision making. In Dovers' terminology, they are 'shallow' rather than 'deep' targets for SEA. The SEA Protocol therefore takes assessment of strategic decision making a stage further, albeit on a discretionary basis, as it can be applied to policies and legislation. ${ }^{50}$ However, there have been criticisms of the Protocol (especially among non-governmental organizations (NGOs)), for failing to go as far as it could ${ }^{51}$ indeed the final version of the Protocol is far more limited than earlier drafts. ${ }^{52}$

\footnotetext{
${ }^{47}$ See Commission Communications, nn. 22 and 24 above.

${ }^{48}$ These include a watering down of environment protection in favour of economic development, including further corporate-led globalization, such as the privatization of energy, water and health; a failure to deal with issues of global debt and poverty, without which sustainable development cannot be realized; and a lack of concrete proposals for action, such as new environmental treaties.

${ }^{49}$ See J. De Mulder, n. 46 above, at 9.

${ }^{50}$ SEA provisions in some jurisdictions do this currently. See S. Marsden, 'Why is Legislative EA in Canada Ineffective and How Can it be Enhanced?', 18:3 Environmental Impact Assessment Review (1998), 241. In Europe see the Dutch Environmental Test: S. Marsden, 'Legislative EA in the Netherlands: The E-Test as a Strategic and Integrative Instrument', 9:3 European Environment (1999), 91.

${ }^{51}$ See J. De Mulder, n. 46 above, at 2-3. Mandatory application to policies and legislation could have been required, for example.

${ }^{52}$ See S. Marsden, n. 25 above.

Procedural provisions of the SEA Protocol are very similar, if not identical, to those of the SEA Directive. For example, the definitions of plans and programmes are identical, although in the Directive 'authority' is defined as an authority 'at national, regional and local level' ${ }^{\prime 3}$ The definition of SEA is also very similar to the definition of environmental assessment under the SEA Directive, although the SEA Protocol goes further and includes the evaluation of likely environmental and health effects. ${ }^{54}$ The Protocol must be applied to the same plans and programmes as the Directive, although regional development is an additional sector, and mining is part of the industry sector. Sectoral plans and programmes must set the framework for future development consent of projects for which an EIA is required under national or international law; Annex I (based on Appendix I of the Espoo Convention) $)^{55}$ and Annex II (based on Annex 2 of the EIA Directive), set out relevant projects. Similar provisions to those discussed above regarding the SEA Directive also allow discretionary SEA under the Protocol.

Jendroska and Stec state that even minor modifications to supplement the obligations envisaged in the SEA Directive were not accepted by the EU Member State negotiators during the work on the draft SEA Protocol. ${ }^{56}$ An example concerns the fact that a Norwegian-inspired effort to introduce the requirement of a notification document was deleted at the end of the negotiation process, even though such a document is part of EIA practice in a number of countries, including EC Member States.

With regard to consultation and public participation, there are some differences. The SEA Protocol does not contain a provision for providing information on the decision taken regarding the plan or programme. Unlike the Directive, the Protocol includes an (albeit discretionary) provision in Article 6(3) to involve the public to decide on the content of the environmental report (scoping). However, as with the SEA Directive, the SEA Protocol has arguably also failed to adequately implement the Aarhus Convention, because it has not included the definition of 'the public concerned', found in Article 2(5).

Of the other conditions that must be satisfied, reasonable alternatives must be considered in the environmental report in accordance with Article 7(2) - a very similar provision to Article 5 of the SEA Directive; and

\footnotetext{
${ }^{53}$ See SEA Directive, n. 2 above, Article 2(a).

${ }^{54}$ See SEA Protocol, n. 3 above, Article 2(6).

${ }^{55}$ This Annex has been extended (and became almost identical to Annex I of the EIA Directive) by the amendment of the Espoo Convention during the Third Meeting of the Parties (Cavtat, 1-4 June 2004).

${ }^{56} \mathrm{~J}$. Jendroska and S. Stec, 'The Kyiv Protocol on Strategic Environmental Assessment', 33:3-4 Environmental Policy and Law (2003), $105-110$.
} 
Annex IV(8) emphasizes the importance of Article 7(2) - Annex IV(8) being almost identical to Annex I(h) of the SEA Directive. Under Article 11(2), during the decision-making process, reasons must be given for adopting a plan or programme 'in the light of the reasonable alternatives considered' - again this is very similar to Annex I(h) of the Directive. With regard to the acknowledgement of uncertainty, Annex III, paragraph 5 provides that where there is discretion as to whether plans and programmes are to be assessed, one of the criteria for determining likely significant effects is the nature of the environmental, including health, effects such as probability, duration, frequency, reversibility, magnitude and extent .... Further, paragraph 6 cites 'the risks to the environment, including health'. Similar provisions are included in Annex II, paragraph 2 of the Directive.

Finally, with regard to monitoring, Article 12(1) of the Protocol is almost identical to the requirement in Article 10 of the Directive, as it requires each party to monitor effects 'to identify, at an early stage, unforeseen adverse effects and to be able to undertake appropriate remedial action'. Monitoring measures must be stipulated in the environmental report in accordance with Annex IV(7) - again, this is very similar to Annex $\mathrm{I}(\mathrm{g})$ of the Directive. Provisions concerning the decisionmaking process are similar to the SEA Directive in that Article 11 of the Protocol requires the same as Article 9(1) of the Directive, with monitoring results to be made public, in accordance with Article 12(2).

The SEA Protocol is subject to review by the parties under its Article 14, which deals with the Meetings of the Parties to the Convention. There are a number of elements to this, outlined in paragraph 4 , which include the need to improve procedures, exchange information, and consider and adopt proposals for amendment.

A likely future amendment might concern the improvement of the quality control provision. Article 12 of the SEA Protocol is considered weaker than the requirement in the SEA Directive. ${ }^{57}$ This is rather surprising, as even the Commission's representative admitted during the negotiations that this requirement in the SEA Directive could have been stronger, and the 5year review of the EIA Directive has proven the need for such a provision..$^{58}$ In an European Environmental Bureau seminar report it was rightly stated that quality control is a major problem with project level EIA, and it was concluded that:

We learn from this experience in implementing the SEA Directive. Key issues will be who is responsible for quality

\footnotetext{
${ }^{57}$ Ibid., at 108.

${ }^{58}$ Commission of European Communities, Five-Year Report to the European Parliament and Council on Application and Effectiveness of EIA Directive (European Commission, 2003).

control, what power do they have over the decision-making process, do they have competence in environmental matters, and do they have sufficient resources for the job ${ }^{59}$

These questions are also relevant regarding the application of the SEA Protocol. But, given the fact that the Implementation Committee of the Espoo Convention has only started the real work quite recently, one might conclude that compliance issues regarding the SEA Protocol, such as the quality of future environmental reports, are not an immediate concern.

A background paper for a work plan on the Protocol that was circulated by the UNECE at the end of 2003 indicated that the UNECE was keen to encourage broad application of the Protocol. ${ }^{60}$ The first Meeting of the Signatories, however, which was part of the third meeting of the parties of the Espoo Convention, reflected a more cautious approach. Due to financial constraints, the part of the approved (Espoo) work plan that deals with the SEA Protocol has only three items on the schedule, with guidance subsequently released on public participation, subregional cooperation and on good practice. Priority will be given for developing the necessary institutional arrangements for the first meeting of the parties of the SEA Protocol. Some already initiated activities concern capacity building (in collaboration with UNDP) and the elaboration of a manual. ${ }^{61}$

\section{TOWARDS SUSTAINABILITY IMPACT ASSESSMENT (SIA)?}

The need to implement the SEA Directive has drawn more attention to the linkage between 'environmental' assessment and other types of appraisal that include aspects of the two other 'sustainable development' pillars: economic and social considerations.

The UK's 2003 guidance document on applying the SEA Directive to the planning system has built on experience from 10 years of sustainability appraisals:

The integrated treatment of economic, environmental and social issues is a key principle of the Government's Sustainable Development Strategy, set out in 'A Better Quality of Life: A strategy for sustainable development for the UK'. Planning authorities are already required to have regard to economic, environmental and social considerations when preparing development plans, and Policy Planning Guidance

\footnotetext{
${ }^{59}$ P. Hamblin, 'Summary of the Strategic Environmental Assessment seminar', SEA Making a Difference, Seminar report (EEB, March 2004), at 39.

${ }^{60}$ UNECE, Preparatory Meeting for the First Meeting of the Signatories to the Protocol on Strategic Environmental Assessment, Background Paper Presenting Possible Elements for a Work Plan for the SEA Protocol (Geneva, 27-28 November 2003).

${ }^{61} \mathrm{lbid}$.
} 
notes and other ODPM [Office of the Deputy Prime Minister] publications reflect this approach ... Subject to approval by Parliament, Sustainability Appraisal will be mandatory for Local Development Documents (LDDs) and Regional Spatial Strategies (RSSs) under the Planning and Compulsory Purchase Bill. It is intended to define the future requirements for Sustainability Appraisals so as to make clear to authorities that in carrying them out, they must fully meet the requirements of the SEA Directive. ODPM will produce guidance for authorities on sustainability appraisal when the new planning system is brought into effect. This will give further details on social and economic issues to be addressed and on the relationships between SEA and Sustainability Appraisal ... Meanwhile, the present guidance gives some indications of how an SEA can form part of a Sustainability Appraisal which also examines the social and economic effects of a plan. These parts of the guidance do not aim to be comprehensive, but only to suggest what types of effect could be considered beyond the scope of SEA and how they might be measured and presented..$^{62}$

This excerpt reveals how complex the institutional setting for a policy towards sustainable development including the application of SEA - may become. These complexities could already be foreseen, given some of the theoretical background.

Hardly 2 years after Agenda 21 was adopted in Rio, Dalal-Clayton suggested that a framework for Sustainability Analysis needed, inter alia, to comprise a suite or 'tool kit' of methodologies and approaches, which:

- explicitly focus on the trade-offs between the biophysical, social and economic aspects of projects, programmes and policies, recognizing that these take place within a framework of political decision making;

- are undertaken in a systematic, integrative and transparent way;

- are participative (not just consultative), to the extent possible and practicable in the context of prevailing socio-political circumstances;

- need to operate within a set of defined criteria and guidelines for sustainable development, recognizing that these may often be best practice approximations; and

- recognize that environmental assessment is a major point of departure because it is a process which is well institutionalized in policy and law. ${ }^{63}$

\footnotetext{
${ }^{62}$ Strategic Environmental Assessment Directive: Guidance for Planning Authorities. Practical guidance on applying European Directive 2001/ $42 / E C$ 'on the assessment of the effects of certain plans and programmes on the environment' to land use and spatial plans in England (Office of the Deputy Prime Minister, October 2003), at 9, found at <http://www.odpm.gov.uk/stellent/groups/odpm_planning/ documents/page/odpm_plan_026670.pdf $>$. See also R. Therivel and P. Minas, 'Ensuring effective sustainability appraisal', 29:2 Impact Assessment and Project Appraisal (2002), 81.

${ }^{63}$ D.B. Dalal-Clayton, S. Bass et al., National Sustainable Development Strategies: Experience and Dilemmas, Environmental Planning Issues No. 6 (IIED, 1994).
}

So it is no wonder that both practitioners and scholars try to find more manageable approaches, like George who stated, after examining the UK's objectives-based sustainability appraisal practice, that a criterion-based approach might offer advantages regarding the practicality of the appraisal or assessment. ${ }^{64}$ Others, like Fischer, however, stick to the objectives-led approach and fear too much flexibility and adaptability:

... Some of the main reasons for conducting SEA ... include a better consideration of the environment in decision making for sustainable development which is not likely to be achieved in the absence of objectives-led pre-structured approaches. ${ }^{65}$

At the latest annual conference of the International Association for Impact Assessment (Vancouver, April 2004), Dalal-Clayton and Sadler gave an overview of the current status of the 'next generation' of more integrated assessment tools. They indicated that there is a lot of diversity between tools that can be considered as 'sustainability appraisal-approaches'. Concepts, theoretical work and workshops are flourishing all over the world, but they pose the question whether there is anything happening in reality. The major challenge, according to both experts, will be to sharpen the focus and to apply these tools effectively so there is a real impact on decision making.

The latest developments in the EU suggest the need to be more realistic about how far SEA will be implemented. Further to the June 2001 Göteborg European Council that called for 'mechanisms to ensure that all major policy proposals include a sustainability impact assessment (SIA) covering their potential economic, social and environmental consequences', ${ }^{66}$ a system of SIA was to be introduced, which also includes cumulative

\footnotetext{
${ }^{64} \mathrm{C}$. George, 'Sustainability appraisal for sustainable development: integrating everything from jobs to climate change', 19:2 Impact Assessment and Project Appraisal (2001), 103. See also R. Therivel, and P. Minas, n. 62 above.

${ }^{65}$ T. Fischer, 'Strategic Environmental Assessment in Post-Modern Times', 23:2 Environmental Impact Assessment Review (2003), 167. ${ }^{66}$ Presidency Conclusions, Goteborg European Council (15-16 June 2001). SIA has been defined by the Commission in the context of the EU sustainable development strategy as follows: 'The elaboration and implementation of all EU policies must be informed by the principles of the EU sustainable development strategy. This will be achieved, inter alia, by introducing sustainability impact assessment for all major policy proposals, analysing their economic, social and environmental consequences including those for developing countries'. See European Commission, The EU and the World Summit on Sustainable Development, Frequently Asked Questions About the EU and its Position on the World Summit on Sustainable Development in Johannesburg, (European Commission, undated), found at <http://europa.eu.int/comm/environment/wssd/qa general_en.html>. The disadvantages of SIA are similar to sustainable development, as the environment is (in theory at least) given an equal weighting in the process, which may result in trade-offs in favour of economic issues especially. Many prefer to retain EIA (or SEA for policies, plans and programmes) tools, which were originally intended to advance environmental protection.
} 
impact assessment (CIA), cost-benefit analysis (CBA) and health impact assessment (HIA) ${ }^{67}$ This was not that new, as already in May 1998 the Commission in a Communication had proposed that all its major policy proposals would be subject to an EIA. This was endorsed by the European Council in June 1998 in Cardiff. ${ }^{68}$

The EU's Action Plan 'simplifying and improving the regulatory environment' that was made public on 5 June 2002, however, made clear that the intention was to come to a 'consolidated and proportionate instrument for assessing the impact of its legislative and policy initiatives, covering regulatory impact assessment and sustainable development (in the economic, social and environmental fields) and incorporating the existing instruments and methods' ${ }^{69}$ The subsequent communication from the Commission on Impact Assessment ${ }^{70}$ did not elaborate on SIA. The Commission's impact assessment process consists of two stages: a preliminary assessment; and an extended impact assessment. In the latter stage, the scope should include an in-depth analysis of the potential impacts of the proposal on the economy, the society and on the environment. ${ }^{71}$ Annex 2 of this communication offers some additional information on the main components of the extended impact assessment, but does not go beyond some vague generalities.

It appears that the obvious need to integrate the several existing separate impact assessment procedures has survived as the only objective of the Commission. While such a streamlined approach is probably essential to offset 'assessment fatigue', the primary focus on sustainable development - and specifically on environmental sustainability - seems to be lost. As SIA differs significantly from regulatory or business impact assessments, clear

\footnotetext{
${ }^{67}$ These are well-established tools of impact assessment, some of which are required under legislation. Cumulative impact assessment $(\mathrm{CIA})$ commonly refers to the assessment of environmental impacts from a collection of associated developments whereby the impact in combination is often much greater than the impact of the individual developments. Cost-benefit analysis (CBA) is a longestablished tool used to determine the economic feasibility of a proposal. Health impact assessment (HIA) is a process to determine the effects of development upon human health.

${ }^{68} \mathrm{D}$. Grimeaud, 'The integration of environmental concerns into EC policies: A genuine policy development', 9:7 European Environmental Law Review (July 2000), 210. The 'Cardiff Process' is the name given to the process launched by the European Council at their meeting in Cardiff, in June 1998, requiring different Council formations to integrate environmental considerations into their respective activities, putting Article 6 of the EC Treaty into practice. The related 'Lisbon Strategy' is a commitment to bring about economic, social and environmental renewal in the EU. In March 2000, the European Council in Lisbon set out a 10-year strategy to make the EU the world's most dynamic and competitive economy. Under the strategy, a stronger economy will drive job creation, alongside environmental and social policies that ensure sustainable development and social inclusion. ${ }^{69}$ Commission Communication of 5 June 2002, Action Plan Simplifying and Improving the Regulatory Environment, COM (2002) 278 final, at 7. ${ }^{70}$ Commission Communication of 5 June 2002 on impact assessment, COM (2002) 276 final.

${ }^{71}$ See Presidency Conclusions, n. 66 above.

guidelines should have been developed spelling out its minimum essential characteristics. But this has not been done, and even the EIA approach raises questions. Concerning the latter, the EU's Sixth EAP places a legal obligation on the Commission to give "consideration, prior to their adoption, of whether actions in the economic and social fields contribute to and are coherent with the objectives, targets and time frame of the Programme ${ }^{72}$ This suggests the need to set minimum environmental requirements within an integrated impact assessment system, and an 'objectives-led' approach reflecting the priorities set by the Sixth EAP Thematic Strategies.

When reading an extended impact assessment on a proposal for a directive such as on services in the internal market, it is amazing how brief the analysis of the environmental impact can be. ${ }^{73}$ After a previous report $^{74}$ indicated the potential risks of introducing a poorly prepared and framed SIA-approach, Wilkinson et al. reviewed in a recent Commission report ${ }^{75}$ whether and how sustainable development considerations have been addressed in the extended impact assessments done in 2003. Their conclusions are quite negative and include the poor quality and limited number of the assessments undertaken. Factors that have contributed to this situation include the absence of a formal quality control mechanism and the lack of an institutional framework within which 'learning by doing' can take place in practice. Furthermore, a lack of transparency in the impact assessment system is mentioned, as well as a non-systematic way of selecting Commission proposals for an impact assessment. The report states also that none of the impact assessments fully followed the Commission's Impact Assessment Guidelines, ${ }^{76}$ whilst the sustainable development issues in the Guidelines are described as: 'brief, not easy to understand, and insufficiently detailed to be of practical use in an extended impact assessment'. ${ }^{77}$

The impact assessment system, as being undertaken at present by the Commission, is, however, not the only

\footnotetext{
${ }^{72}$ See Commission Communication, n. 24 above.

${ }^{73}$ In this case it is only two pages. See proposal for a Directive of the European Parliament and of the Council on services in the internal market, SEC (2004) 21, and Commission Staff Working Paper of 13 January 2004, Extended Impact Assessment of Proposal for a Directive on Services in the Internal Market, COM (2004) 2 final, at 52, found at <http://europa.eu.int/comm/internal_market/en/services/ services/docs/2004-impact-assessment_en.pdf>.

${ }^{74}$ A. Kraemer and D. Wilkinson, EU Environmental Governance: $A$ Benchmark of Policy Instruments with a Focus on Agriculture, Energy and Transport (ECOLOGIC-IEEP, June 2002). This report refers briefly to SEA when dealing with the issue on how to involve Member States in impact assessments.

${ }^{75}$ D. Wilkinson et al., Sustainable Development in the European Commission's Integrated Impact Assessments for 2003 (Institute for European Environmental Policy (IEEP), April 2004).

${ }^{76}$ See Commission Communication, n. 70 above.

${ }^{77}$ See D. Wilkinson et al., n. 75 above.
} 
one, as DG Trade started a process in 1999 to apply sustainability impact assessments to its trade policies. ${ }^{78}$ A major focus of this process was and still is to develop a methodological framework next to the 'experimental' application of SIA. At present, it is being acknowledged that the methodology still needs improvement. Again, the similarity to the basic EIA approach is striking. ${ }^{79}$ The European Community is not alone in this approach, as the USA and Canada started similar exercises, built on their experiences with the Commission for Environmental Cooperation as part of NAFTA. ${ }^{80}$ Having learnt some lessons, key figures in these North American assessments remain, however, prudent about the potential of the instrument. ${ }^{81}$ Given the complexity of the trade issue, it could be questioned if SIA in this context will ever go beyond the academic environment. ${ }^{82}$

In order to address some of the major problems concerning the application of impact assessment by the Commission, one might wonder if a defined legal environment could be helpful. On the other hand, one cannot dismiss the fact that the legal foundations of EIA have not been able to guarantee the proper implementation of the instrument, so it is questionable if a legal framework would be convincing enough for a more adequate impact assessment approach.

\section{CONCLUSIONS}

The SEA Directive and SEA Protocol are both significant requirements for SEA. Both meet the conditions argued by Partidario and Clark to be necessary for SEA to contribute to sustainability, albeit to varying degrees. The SEA Directive has a far better policy framework in place for sustainable development, including explicit recognition of the precautionary principle. However, this is not surprising, given the emphasis put on this by the EU, particularly under the Treaty and in its series of Action Programmes. While both the Directive and Protocol are fairly limited in application to plans and programmes, the Protocol goes further in encouraging application to some policies and legislative

\footnotetext{
78 See European Commission, Sustainability Impact Assessment (January 2004), found at <http://europa.eu.int/comm/trade/issues/ global/sia/index_en.htm>.

${ }^{79}$ C. Kirkpatrick and N. Lee, Further Development of the Methodology for a Sustainability Impact Assessment of Proposed WTO Negotiations (IDPM-Manchester, 5 April 2002), at 10.

80 The North American Commission for Environmental Cooperation was created under the North American Agreement on Environmental Cooperation.

81 Impact Assessment of International Trade (IAIA conference, Vancouver, 27 April 2004). See also P.B. Underwood, and C.A. Alton, n. 7 above.

${ }^{82}$ N. Lee and C. Kirkpatrick, 'Methodologies for sustainability impact assessments of proposals for new trade agreements', 3:3 Journal of Environmental Assessment Policy and Management (2001), 409-410.
}

proposals as well. The Directive leaves it up to Member States to go further than its requirements if desired, and some European countries have already applied SEA to policies and legislation. ${ }^{83}$

It is reasonable to assume that as experience is gained under both instruments there will be changes that may well result in greater exposure of higher order decisions to public input and evaluation. It is hard to deny the formal changes that the Aarhus Convention has already brought in this direction, with the European Directive on Public Participation, ${ }^{84}$ and moves by the European Commission to subject all major policy and regulatory initiatives to assessment of economic, social and environmental impacts. The outcome of the future implementation of the Public Participation Directive remains to be seen, but the above-mentioned review of the Commission's impact assessment system gives not much reason for great optimism. If environmental policies are currently not as integrated as they could be, further, possibly 'deeper' application of SEA could be on the agenda of the future. But the question remains whether there is enough political willingness to do so.

The current application of impact assessment relies heavily on discretion and seems unable to gather much institutional support. Even the newly established SEA Directive seems to be already out of fashion. It might be an indication that in the review of the 5-year work programme by the EU Commissioner for the Environment, there is no mention of the adoption of the SEA Directive. ${ }^{85}$ Also, a recent OECD publication on 'implementing sustainable development' contains rather worrying language:

The vast majority of OECD countries do not subject environmental protection laws to a systematic review of their economic consequences. Moreover, there have been instances when cost-benefit analysis has been poorly integrated into policy decisions. In contrast to the lack of systematic economic assessments of environmental programmes, the integration of environmental concerns in public decision-making processes at the project level is better established. ${ }^{86}$

This observation is contrary to one of the conclusions of a recent IEEP study stating that the Commission's

\footnotetext{
83 These countries include the Netherlands and Finland.

${ }^{84}$ Council Directive 2003/35/EC of the European Parliament and Council of 26 May 2003 providing for public participation in respect of the drawing up of certain plans and programmes relating to the environment and amending with regard to public participation and access to justice Council Directives 85/337/EEC and 96/61/EC, [2003] OJ L156/17.

${ }^{85}$ European Commission, Five Years as European Commissioner for the Environment (European Commission, June 2004), found at <http://europa.eu.int/comm/commission_barroso/dimas/policies/ policies_en.htm>.

${ }^{86}$ Organization for Economic Cooperation and Development, Implementing Sustainable Development: Key Results 2001-2004 (OECD, 2004), at 4.
} 
impact assessments gave most attention to economic impacts and only limited attention to environmental and social impacts. ${ }^{87}$ The Commission Working Document of 1 June 2004 acknowledges that the Cardiff Process has produced mixed results and enumerates several shortcomings, such as a general lack of consistency and insufficient political commitment. ${ }^{88}$ This working document concludes with a number of suggestions to increase the effectiveness of the process. Impact assessments at Community level are mentioned as potential powerful instruments, whilst stringent implementation of the EIA and SEA Directives is considered as a key to advancing environmental integration. ${ }^{89}$ However, it remains doubtful if these assessment instruments can reverse the trend. As Sheate observes:

...the Cardiff Process - which philosophically supports EIA and SEA and an environmental perspective of sustainable development - appears to be struggling against the overwhelming dominance of the Lisbon Process. The Cardiff Process' own integration with the Lisbon Process risks it becoming the Cinderella of sustainable development, and is perhaps a metaphor for the risks to environmental protection of complete absorbance into (rather than integration with) the socio-economic aspects of policy making. ${ }^{90}$

Beyond the EU, within the UNECE, the Cavtat Declaration adopted on the occasion of the third meeting of the parties of the Espoo Convention is also not ambitious, and a draft paragraph mentioning this Convention and the SEA Protocol as cornerstones on which to build more holistic, integrated forms of impact assessment and environmental management, as identified in the Johannesburg Plan of Implementation, did not survive, in part due to resistance from many EU Member States and the Commission. ${ }^{91}$ Without being unduly pessimistic, it may well be that sustainability will remain a word with different meanings, while SEA, rather than integrating environmental considerations into policies, plans and programmes, may end up trading them off with economic and social ones, as in SIA.

Simon Marsden is a Lecturer in Law at the School of Commerce, University of South Australia. He holds a $\mathrm{PhD}$ in SEA. He has previously worked as a solicitor at the Environment Agency of England and Wales, where he assisted in providing legal advice to the Agency on the implementation of the SEA Directive.

Jan De Mulder is a Senior Researcher in the Department of Public International Law at the University of Ghent. He is legal counsel with the Environment Administration of the region of Flanders-Belgium, and has previously been a Belgian delegate to the SEA Protocol negotiations.

\footnotetext{
${ }^{87}$ Institute of European Environmental Policy, The Future of EU Environment Policy: Challenges and Opportunities (IEEP, December 2004), at 25.

${ }^{88}$ European Commission, Integrating environmental considerations into other policy areas - A stocktaking of the Cardiff process, working document, COM (2004) 94 final, at 31.

89 Ibid., at 35-36.

${ }^{90} \mathrm{~W}$. Sheate, 'Changing conceptions and potential for conflict in environmental assessment - Environmental integration and sustainable development', 3:5 Environmental Policy and Law (2003), 229.
}

${ }^{91}$ See UNECE, n. 60 above. 